Open Access

\title{
Complexity in the oil and gas industry: a study into exploration and exploitation in integrated operations
}

\section{Fabio Bento(1)}

\begin{abstract}
A common organizational response to the recognition of complexity is the consolidation of collaborative work forms. In the oil and gas industry, developments in communication and automation technologies have enabled the implementation of collaborative environments called integrated operations $(\mathrm{IO})$. The $\mathrm{IO}$ concept is usually described as the integration of people, work processes and technology with the goal of facilitating decision-making and process optimization. This study contributes to the study of the knowledge dimension of IOs by investigating the exploitation of existing practices and the exploration of new possibilities in complex adaptive processes. Data collected through observations of practices reveal changes in patterns of interaction among oil platform operators relocated to an $1 \mathrm{O}$ facility and the emergence of a complex interplay between exploitation and exploration. Rather than a spatial or temporal separation between the two processes, the findings illustrate an organic relation between exploration and exploration in the context of uncertainty and local adaptations in oil production. The discussion of findings provides elements to reflect upon knowledge management in the oil and gas industry.
\end{abstract}

Keywords: Integrated operations, Complexity, Systems, Exploration \& exploitation, Oil \& gas, Adaptive processes, Interactions, Learning in organizations, Knowledge

\section{Background}

The concept of integrated operations (IO) refers to the emergence of new work forms characterized by technological developments that enable real time data sharing and communication among multidisciplinary expertise, geographical areas and organizational settings. Since the initial initiatives in the early 1990s, the concept of integration has permeated changes in the operational model of most major oil and gas companies. In most companies, the concept of integration is practiced with the implementation of shared workspaces where onshore and offshore personnel interact with the use of video conferencing technology (Steiro \& Torgersen, 2013). Such data sharing facilities are usually called collaboration or operation rooms. The overriding objective is an integration of people, work processes and technology (Lima, Lima, Quelhas, \& Ferreira, 2015). According to Rosendahl and Hepsø (2013), the Norwegian continental shelf is widely perceived as the geographical area in which the concept of IO is most consolidated, although it has permeated organizational changes in many countries.

(c) The Author(s). 2018 Open Access This article is distributed under the terms of the Creative Commons Attribution 4.0 International License (http://creativecommons.org/licenses/by/4.0/), which permits unrestricted use, distribution, and reproduction in any medium provided you give appropriate credit to the original author(s) and the source, provide a link to the Creative Commons license, and indicate if changes were made. 
Integrated operations can be intuitively defined as shared spaces where multiple operations are remotely controlled in a collaborative manner with the use of information and communication technologies. IO is more than a simple adoption of new technology but a major organizational change in terms of perceptions of limitations of deep-rooted assumptions in the oil and industry. As described by Lochmann (2012), there is a recognition of complexity in oil production surveillance breaking with a once dominating approach in which production processes could be divided, understood and modelled separately. Similarly, OLF (2005) states that IO processes break with a traditional way of structuring production operations in a sequential manner by introducing a parallel collaborative process in which processes and agents are interdependent.

The reduction of accommodation costs by moving personal onshore is a common motivation to implement IO. However, the expected benefits of IO go beyond that. It is usually expected that IO will promote an organizational environment that facilitates faster and better decision-making. However, more recent research have addressed human and organizational challenges that had been little explored in earlier studies. Initial research on integrated operations often demonstrated an overoptimistic expectation on IO and a bias on technology issues (Hepsø, 2006).

Researching IO in oil and gas is important for several reasons. First, there is the importance of this industry to global and national economies. This study was conducted in a context of international crisis with an oil price decline of as much $60 \%$ bringing important economic and social consequences. However, the oil price decline is not the only crisis faced by oil companies. There is a knowledge crisis one expressed by the need to develop new strategies to identify the emergence and dissemination of new knowledge in order to thrive in a complex and uncertain market environment. Second, there is the industry need to understand the knowledge dimension of IO beyond its technological dimension. The implementation of IT-based knowledge management tools has facilitated the storage of information (Grant, 2013). On the other hand, the capacity to learn, develop and share knowledge seems highly dependent on how members interact. Such tools are little relevant in addressing tacit dimensions of learning and situated practices that have a highly experiential character in which knowing and doing cannot be separated from each other (Gherardi \& Nicolini, 2002). Hence, there is a here an industrial need to understand more about the human interactional aspect of IO environments on the interplay between existing knowledge and the exploration of new one which may lead to the emergence of innovation.

\section{Exploration and exploitation related to open innovation}

Understanding exploitation and exploration processes in organizations is relevant to open innovation in at least three ways. First, as claimed by Yun, Won and Park (2016), (p. 22), open innovation is based on the flow of technologies and knowledge across the formal boundaries of firms. From this perspective, one may argue that it is also important for open innovation to understand the flow of knowledge and networks of diffusion at the organizational level. In this respect, West and Gallagher (2006) state that open innovation involves facilitating and integrating not only external but also internal sources of innovations. Second, there is the recognition that innovation always involves a "quest in the unknown" as asserted by Han (2017, p. 2) and therefore there is the need to understand how exploration occurs in organizational settings. Third, there is a relation between the 
emergent dimension of knowledge and open innovation as described by Dougherty (2017). Emergence is indeed a central characteristic of complex systems. This means recognizing that knowledge that can potentially lead to innovation may also emerge in organizational units that have not initially been designed for exploratory purposes such as the IO facility studied here. Furthermore, as stated by Yun et al. (2016), there is an intrinsic relation between open innovation, complex adaptive systems and evolutionary change. As recognized by the authors, companies struggle to survive if they do not meet the needs of their surrounding market environment. In evolutionary terms, this challenge may be understood as the need to match the complexity of an ever-changing environment by allowing internal variation and facilitating processes of interaction from which innovation may emerge (Andersen, Ree \& Sandaker, 2010). This study aims at contributing to understanding this relation by looking at exploitation at exploration at the organizational level from an evolutionary perspective: therefore interaction and variation are the central elements of the conceptual framework operationalized here.

\section{Article structure}

In the first part of the article, I review literature conceptualizing knowledge and learning in IOs. As the review shows, concepts such as communities of practice, capability and resilience have brought important insights but did not explicitly approached exploitation and exploration. In the second part, I articulate a conceptual framework of complexity. The present study contributes to this field by applying a frame reference of complex systems to explore processes of interaction and knowledge in IO settings. Organizational responses to complexity raises questions about the relation between exploring new alternatives leading to the development of new knowledge and the exploitation of preestablished knowledge (Levinthal \& March, 1993; March, 1991). In the third part, I present findings from an empirical observation of processes of interaction in a remote control operation room in one major oil and gas company. In the last part, I discuss findings highlighting changes in interaction patterns and a complex co-existence in time and space of exploitation and exploration.

\section{Knowledge in integrated operations: A review of the literature}

The simple implementation of common technology platforms or common access to information in the form of databases does not automatically grant successful collaboration or knowledge creation. Therefore, patterns of interaction are important. Hepsø (2009) places IOs as forms of common information spaces that expectedly promote multidisciplinary collaboration and knowledge creation. As described by Hepsø (2009), common information spaces such as IOs are dynamic spaces which are mostly unstable and mutable. These are multidisciplinary spaces where different communities of knowing bring their own expertise and engage in process of communications. In such heterogeneous settings, there is a need for a common understanding in order to fulfill its function. For Filstad, Hepsø and Skarholt (2013), (p. 77), "knowledge sharing in integrated operations across boundaries occurs within an existing or emerging governance structure, where colleagues collaborate in virtual teams, where knowing how to perform professionally is key for problem solv-

ing". Another important factor related to successful collaboration and knowledge sharing in a broader perspective and in the specific case of IO is trust (Filstad \& Hepsø, 2009). 
The willingness to share sensitive information and engage in exploration of new knowledge requires trust often in the context of informal social practices.

Integrated operations as communities of practice

The concept of communities of practice developed by Lave and Wenger (1991) focusing on the social interactional context in which practice takes place is often referred to in the study of IOs (Almklov, Østerlie, \& Haavik, 2014; Ose \& Steiro, 2013). The practice-based orientation has a rather pragmatist perspective on knowledge by assuming that knowing and doing are intrinsically connected. This connection takes places in spaces of coordinated interaction among members who have a common activity sharing a community identity and overlapping values. On the other hand, communities of practice are less susceptible to management control due to the some of the characteristics listed by Hislop (2009): evolving, shaped by common values, organic, self-managing and non-hierarchical. Therefore, often knowledge management strategies explicitly aim at identifying communities of practice and nurturing mechanism of social interaction and giving them some degree of autonomy.

\section{Resilience and capability}

Apneseth, Wahl and Hollnagel (2013), and Hollnagel (2013) recognize risk in drilling and offshore operations and conceptualize learning as a key dimension of resilience engineering. For them, a resilient organization is one that has the capacity to respond and adapt to external and internal perturbations. Resilience involves the abilities to monitor, to respond, to anticipate and to learn. The capability approach applied by Henderson, Hepsø and Mydland (2013) derives from the metaphor of ecology to represent the dynamics of emerging situation in IOs. The ecology metaphor calls for the limitation in understandings the organizational and capabilities in the oil and gas industry in terms of fixed hierarchies and equilibrium markets. The consolidation of IO environments means important changes in terms of interactions for various organizational agents (Larsen, 2013; Rosendahl, Egir, Due-Sørensen, \& Ulsund, (2013). Such changes are not only technical decisions but involve alterations in practices and unwritten codes that can either open or close for variation and the exploration of new knowledge.

This brief review of the literature shows that in spite of conceptual differences, it is possible to identify a common interest in understanding knowledge sharing, situated learning and emergence in conditions of uncertainty. The present study conceptualizes the IO workspace in terms of interactions constituting a unit of adaption nested in an organizational structure.

\section{Exploration and exploitation in adaptive processes}

The trade-off between exploitation and exploration in complex adaptive systems is a matter of interest in different fields ranging from genetics to the decisions about allocations of resources in organizations (Axelrod \& Cohen, 2000). Complexity theorists have a common interest in the emergence of patterns and novelty from multiple processes of interactions among different agents of complex systems (Byrne \& Callaghan, 2014; Johnson, 2001; Padgett \& Powell, 2012). The role and importance of knowledge have long been a central point of interest in studies of adaptive processes (Gupta, Smith \& Shalley, 2006; 
Holland, 1975; Lavie, Stettner \& Tushman, 2010; March, 1991; Miller, Zhao \& Calantrone, 2006). Table 1 shows definitions, managerial attitudes and activities usually associated to exploitation and exploitation:

It is usually argued that organizations face the challenge of reaching a balance between exploration and exploitation in order to preserve their adaptive capabilities. The challenge in presented by March (1991) in the following terms:

Adaptive systems that engage in exploration to the exclusion of exploitation are likely to find that they suffer the costs of experimentation without gaining many of its benefits. They develop too many underdeveloped new ideas and too little distinctive competence. Conversely, systems that engage in exploitation to the exclusion of exploration are likely to find themselves trapped in suboptimal stable equilibria (p. 71).

Both processes involve at least some degree of learning as even when replicating already existing practices, individuals in organizations accumulate experiences producing changes even if only of incremental character (Gupta et al., 2006). Organizations have explicit and implicit mechanisms that facilitate exploration and exploitation. Different strategies and policies might explicitly state patterns of exploration and exploitation. Similarly, implicit mechanisms such as unwritten norms and informal everyday patterns of interactions might open or close the possibilities for exploiting existing knowledge and/or exploring new alternatives (Hislop, 2009). For March, (1991), the trade-off between exploitation and exploration involves risks and vulnerability which are further complicated because the two compete for often scarce resources in organizations. Potentially positive returns from exploration are more uncertain and distant in time and space than expected returns from exploitation.

The trade-off also involves tensions between individual knowledge and what March regards as the organizational code comprising the socialization of language, beliefs and practice. In the development of knowledge, there is then a two-way adaptation between individual learning and the organizational code called mutual learning (March, 1991). The organizational code consists of norms, rules and procedures which are expressions of the knowledge stored over time by learning from organizational members. However, there is a tendency in adaptive processes to privilege exploitation of existing alternatives in relation to the exploration of unknown ones in order to consolidate the reliability of performance.

\section{Ambidexterity}

Ambidexterity is a central concept in the study of exploration and exploration in organizational settings. As described by Stettner and Lavie (2014), ambidexterity refers

Table 1 Defining Exploitation and Exploration

\begin{tabular}{lll}
\hline & Exploitation & Exploration \\
\hline $\begin{array}{l}\text { Meaning (Levinthal \& March, } \\
\text { 1993, p. 95) }\end{array}$ & $\begin{array}{l}\text { "the use and development of things } \\
\text { already known". }\end{array}$ & $\begin{array}{l}\text { "the pursuit of new knowledge of } \\
\text { things that might come to be } \\
\text { known" }\end{array}$ \\
$\begin{array}{l}\text { Activities and ideas } \\
\text { usually associated to exploitation } \\
\text { and exploitation (March, 1991, p. 71) }\end{array}$ & $\begin{array}{l}\text { "Exploitation includes such things } \\
\text { efficiency, selection, implementation, } \\
\text { execution" }\end{array}$ & $\begin{array}{l}\text { "Exploration includes things } \\
\text { captured by terms such as search, } \\
\text { variation, risk taking, } \\
\text { experimentation, play, flexibility, } \\
\text { discovery, innovation" }\end{array}$ \\
$\begin{array}{l}\text { Managerial actions enabling } \\
\text { exploitation and exploration } \\
\text { March, 1994) }\end{array}$ & $\begin{array}{l}\text { Restricting variation } \\
\text { Facilitating variation }\end{array}$ \\
\hline
\end{tabular}


to the possibilities and implications of reaching a balance between exploration and exploitation. The main question here is how exploratory and exploitative processes take place and interact in organizations. As reviewed by the authors, most studies argue for a separation of exploratory and exploitative processes in organizations. Such separation can assume different forms: temporal (transitions between exploration and exploitation over time) or spatial (separate organizational units or domains of activities engaging in either exploration and exploitation). Although the authors acknowledge the interplay among different organizational domains, their longitudinal analysis of software firms in the US highlight the third form by exploring via externally oriented modes while exploiting in internal organizational (Stettner \& Lavie, 2014). Their study departs from the assumption that exploration and exploitation involve different kinds of routine and relying on both simultaneously "induces in tension, complexity and coordination challenges that can undermining performance" (Stettner \& Lavie, 2014, p. 1906). On the other hand, the evolutionary perspective offered here focus on adaptation processes and brings an organic perspective towards ambidexterity that will be further discussed in the light of empirical findings.

\section{Variation and selection in complex systems}

Explaining organizational adaptation from an evolutionary perspective requires framing exploration and exploitation in terms of variation, interaction and selection (Axelrod \& Cohen, 2000). The organizational response to an increasing environmental complexity involves changes from an organizational paradigm focusing on control management to one facilitating behavioral variation (Sandaker, 2009). Selection requires a wider range of solutions and practices than on the previous organizational paradigm that focused on standardization and control. In order to match the complexity of the environment, there is a need to allow for variation facilitating the emergence of new solutions and practices in order to cope with an ever-changing environment. The focus on interaction demands looking at webs of influence beyond formal organizational hierarchies and divisions. For instance, there is an increasing recognition of the evolutionary and continuous rather than revolutionary character of processes of change in organizations (Warner Burke, 2013). As highlighted by Andersen et al. (2010), both learning and selection are relatively constant processes in natural systems but it would be a misconception to assume that selection is goal-oriented and necessarily leading to improved outcomes. From this perspective, the very concept of learning loses the rather normative value usually implied by learning organization models. However, organizations use different forms of interventions to engineer selection (March 1994).

The selectionist perspective raises questions regarding dominant organizational assumptions in the oil and gas industries. Oil companies have many characteristics of professional bureaucracies configurations where there is a high degree of specialization (Bremdal \& Korsvold, 2013). In such configurations, skilled professionals require control of their own activities and work in a highly independent manners. In bureaucratic models of organization, there is an embedded focus on standardization and control of unwanted variation. There are structures that restrict interactions to the level of formal processes in order to avoid the risk of undesired variations (Sandaker, 2009). Hollnagel (2013) provides an understanding of the concept of integration that strengthens the choice of complex 
systems as the theoretical framework in this study: "the common sense of 'integration' is to make something 'into a whole'. This means that parts that hitherto were considered separately and that may have functioned separately, become subsumed under a common framework" (p. 345). Integration draws attention to increasing interactions and interdependencies between different parts of a system. That implies in heterogeneity and uncertainty. Bearing that in mind, using the frame of reference of complex systems to understand the concept of integration implies in variation and the exploration of new knowledge.

\section{Complexity and the possibilities for engineering organizational history}

The evolutionary dynamics of organizations have attracted attention from management scholars for many decades. However, further developments in complexity have been accompanied by a redefinition of organizational evolution moving from outcome conceptions to process conceptions (March, 1994). As described by March, the initial conceptions of ordered paths towards efficient outcomes have gradually been substituted by a historical logic of multiple equilibria, branching processes and networks of diffusion in local adaptation processes. There is then space to move from a normative understanding of selection: "there are irreversible branches, thus path-dependence and decisive minor moments. The branch-points, involving factors as mutations, mating, communication contacts, and fortuitous opportunities often seem chancelike in their resolution, yet decisive in their effects on subsequent history" (March, 1994, p. 44). A central theoretical implication of this development is a stronger emphasis on engineering rather than predicting history. In organizational settings, attempts to engineer history can range from large to small interventions that might implicitly aim at changing information flows, altering structure of interactions and/or managing the exploitation and exploration relation. From this perspective, implementing IO settings can be seen as forms of interventions intending to change patterns of interaction hereby bringing implications for exploitation and exploration.

\section{Empirical case}

Most of the organizational research I presented on my literature review focus on developments in the Norwegian oil industry where the concept of IO was initially implemented and is regarded to be in advanced stage of consolidation. However, the case that I analyze here is located in another country and different types of evidence suggest that the very concept of integration has different meanings and implications than in the Norwegian context. The qualitative data was gathered over 6 weeks throughout observations of everyday practices in a large oil and gas company.

In 2009, the company launched a strategic program aiming at integrating operations in Exploration and Production. The expressed aims of the program included increased efficiency, lower operational costs and faster flow of information contributing to effective decision-making. However, its implementation presents itself in varying stages of consolidation in different operational units of the company. The observations were conducted in a facility from where operations in eleven offshore platforms were remotely controlled. This was located in the oldest operational unit of this company that historically generated much of the know-how that was later 
transferred to other units. Some middle managers informally described this unit as one in which changes usually encounter resistance and happen in a slow pace. The implementation of the IO concept here implied in the gradual movement of platform operators to an onshore facility. While in most companies, the IO facility is called collaboration or operation room, in this unit the IO room is called operational control center.

Oil platforms are complex structures where different processes such as drilling, extraction, processing and storing take place. In large platforms, the structure provides accommodation for over two hundred people and helicopter traffic is constant (Booth \& Butler, 1992). The platforms located in the geographical area of this case studied varied in size, production and level of complexity. While some performed all the above processes, others only extracted the natural resource and directed it to other platforms, which initially processed the raw material before it could be transported onshore for refining. Besides oil production, Gas Oil Separation Plants (GOSP) include utility systems that provide energy, water and air to be used in the platform (Devold, 2013). Some platforms provide gas to other platforms in the same area. In this sense, there was a complex network of interdependence and intense information flow among the platforms. In offshore production platforms, the local control room is the central space for monitoring and controlling production processes and safety procedures (Walker et al., 2014). Platform operators are professionals monitoring production processes, storage and assisting oil production teams. In many companies, the concept of integration brought changes to the role of the platform operator by demanding them to be part of distributed teams (Walker et al., 2014).

\section{Research design}

It was difficult to create conditions for classical interview situations due to the long working shifts and the fast-paced routine of the operational control center. Therefore, the methodological choice here was to observe the work routine maintaining dialogues with participants as they conducted and described their own activities in day and night shifts. Data-gathering was characterized by periods when the researcher observed the daily interactions and periods when descriptions of practices were gathered in a dialogical manner with participants (Bryman \& Bell, 2015). Dialogues were transcribed and observations were noted in memos. Recurrent themes were identified and analyzed in an interpretive manner. Observations, field notes, extracts from dialogues and meetings were coded and categorized under two clusters of findings: interactions and local adaptations. Local adaptations were thereafter divided in exploitation and exploration. Data associated with restriction of variation were associated with exploitation while data which were interpreted opening for the possibility novelty was grouped under exploration. The choice of structuring findings in such clusters were theory-driven informed by the conceptual framework of complex systems (the focus on interactions as units of analysis) and conceptualization of units of adaptations by March (exploration and exploitation in local adaptations). This study has thus a qualitative character applying the framework of complexity in an interpretive manner giving space for contextuality and the experience of participants (Tsoukas \& Hatch, 2001). Working with different 
kinds of evidence (observational and dialogical) contribute to bring objectivity to the interpretive character of this study. In this respect, gathering personal experiences from participants and observing practices as they were being conducted provided the opportunity to compare and to some extent cross-check different kinds of data. I present here extracts of data that are conceptually representative of overall findings. The following figure (Fig. 1) illustrates the research rationale and presentation of findings:

In order to protect the anonymity of the company and participants, the country where this study was conducted is not mentioned here. At times, the researcher's lack of technical knowledge of oil production limited the understanding of some processes. This can be regarded as a limitation of this study. However, this limitation was to some extent compensated by the effort to learn about oil production by reading a technical handbook (Devold, 2013) and maintaining a collaborative communication with the company's research and development center in order to clarify the professional language of participants. This helped me to refine the analysis and interpretation of observational data. The data reveals emerging exploratory practices that were not always verbalized as learning in the language spoken by the participants and that could not be anticipated by looking only into the highly exploitative character in which the IO concept was implemented in this company.

\section{Findings}

Understanding changes in the activity of oil platform operators is particularly interesting as it takes place in a context where two dimensions of complexity coexist. First, there is the complexity of production itself in which different processes are interrelated. The operator is in important position in terms overviewing such processes and responding to incidents that might occur. Second, there is the

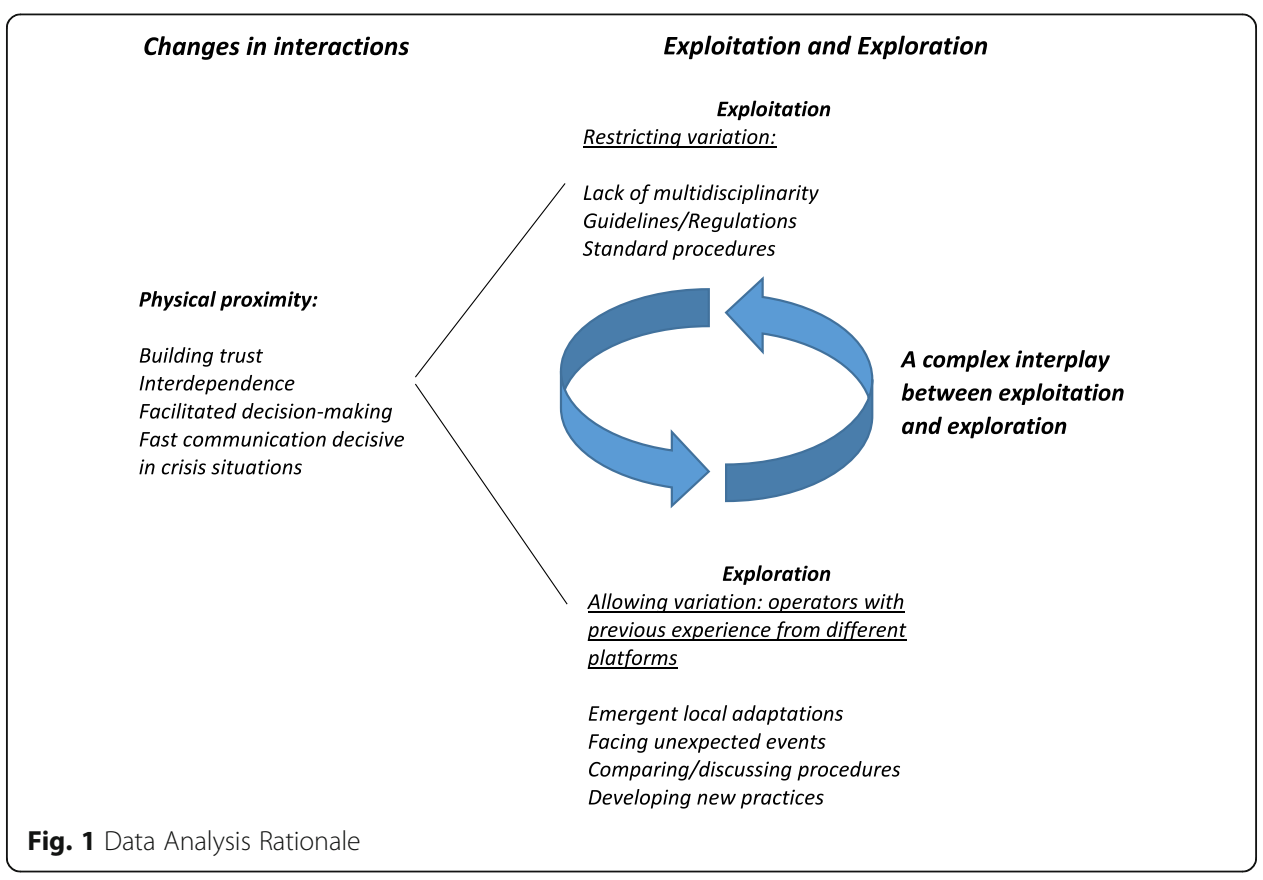


complexity of dynamic processes of interactions and interdependence among different platforms. The observation of changes in interactions patterns brought the integration process brings important implications for exploitation and exploitation in organizational learning. The concept of integration did not assume in this context the character of multidisciplinarity and teleconferencing communication with offshore staff as in other settings, but of a tighter communication and cooperation among operators with diverse previous experiences.

\section{Changes in interactions}

In each shift, twelve operators shared the facility in a rather noisy environment with intense communication with platforms by radio and phone, and alarms ringing indicating potential problems in offshore facilities. There is an intense exchange of information and constant problem-solving between offshore personnel and the operator in the onshore facility.

Operators described the transition from the platform to the onshore facility as a tradeoff. First, there were descriptions of gains in life quality by moving from the stressful confinement environments of the platforms and having more contact with their own families. The second gain was described in terms of proximity and a more direct interaction with operators responsible for other platforms. Operators described increasing and facilitated communication with operators responsible for other platforms due to physical proximity. It was possible to observe that operators in the control room would regularly walk to each other's desk to discuss ongoing issues and were therefore less dependent on radio or phone. This was regarded as particularly positive in critical situations such as recovery from platform shutdowns in which fast communication is often decisive. For instance, the operators of platform that was recovering from a shutdown could walk to the desk of another operator and ask for more gas in order to restart operations. Other operators in the room followed attentively such situations. They could anticipate possible consequences to their own platforms facilitating decision-making and therefore responding faster to unexpected events. As operators described, small incidents can lead to major outcomes to platforms in the same area. In such cases, only the operator has the local knowledge can operate his/her platform, but rapid information exchange with other operators was seen as highly decisive.

The tasks of operators consisted mainly of oil production surveillance, monitoring different processes and safety tests conducted in the platform. Such activities required prior technical knowledge of oil production and regulations from the national oil agency. The normal work shift had a rather cyclical routine starting with receiving a report and discussing possible problems and sometimes unexpected events with operators from the previous shift. In the words of one operator, the normal workday was a "routine that is not really a routine" in which the ongoing standard practices were punctuated by unexpected events, problem-solving and fast decision-making. The physical proximity changed interactions in other ways indicating another important tradeoff. There were gains in terms of consolidating relations of trust and friendship with operators in the same operational unit but also losses in terms of interpersonal relations with offshore colleagues. Physical proximity and consolidation of trust relation created the condition for the emergence of exploration of new possibilities in the operational control center. 


\section{Local adaptations and knowledge: A complex interplay between exploitation and exploration}

In the initial stage of the data gathering period, operators readily described their activities in terms of routines, procedures and standards indicating an exploitative character. At this stage, initial conversations with operators revealed accounts of learning in terms of acquiring pre-established technical knowledge, procedures and regulations. Furthermore, most participants described experiencing an increasing standardization of practices in recent years in the form of a steady increase in norms, standard procedures and in both internal and external auditing by government agencies. In the words of one operator, "now we have more noes than yeses". In this initial period that lasted for a week, learning beyond the acquisition of already existing technical knowledge about written norms and procedures was rarely verbalized by participants .

The non-verbalization of exploration can be exemplified the case of risk analysis meetings that anticipate the transference of operational control from an oil platform to the offshore facility. These meetings usually lasts for two days and follow a "what-if" rationale in which operators, managers and external consultants analyze a list of operational practices and discuss possibilities and potential problems of transferring processes from the platform to the operational control center. I observed a risk analysis meeting with operators that would later be relocated onshore from a relatively large and complex platform, which performs not only oil production but also provides gas to other platforms in the same geographical area. The main risk mentioned by operators both during the analysis meeting and in the room was a possible loss in terms of tacit knowledge acquired with their experience in the platform. One operator explained this dimension of knowledge in the following terms: "you have to learn to feel the platform and that's something you only develop when you are there". On the other hand, learning or knowledge sharing was not mentioned neither by the four operators, the two managers and the two external consultants present in the meeting. In the words of an external consultant that attended the risk analysis meeting, integrated operations "look sometimes very unstructured. We need to make things more uniform. We need to standardize".

However, observations of everyday patterns of interactions and practices show likewise an important exploratory dimension that it is not always described as learning or even as knowledge sharing in the language used by oil platform operators. This took often the form of everyday adaptations and improvements that were locally initiated rather than externally designed. I present three examples of emergent exploratory processes that were observed.

\section{Developing a new practice}

Changes in registration and storage of pressure and temperature of oil reservoirs is one of such changes. In the end of work shift, operators are responsible for producing a spreadsheet showing hourly variations in the temperature and pressure of oil reservoirs. Storing such information is important for safety reasons. During the initial period of implementation of the operational control center, operators would manually take notes and transfer such information from the measurement device program to a spreadsheet. This procedure was regarded as time-consuming and susceptible to errors. By comparing their own practices, operators of different platforms identified the need to develop faster and more reliable forms of storing such 
data and worked on a program that automatically produced the spreadsheet using data from the measurement device program. As they described such innovative and exploratory process were facilitated by the proximity they experienced in integrated environments where problems were identified, different practices were compared and new possibilities were assessed. A common expression used by operators in the room in relation to such processes was "if it works, I want to use it too".

\section{Exploration emerging from problem-solving}

The activity of the platform operator involves a great amount of unexpected problemsolving. As described by participants, such unexpected events represent important situations in which they developed an understanding of the interrelation between different production processes. For instance, in the first days of observations, the sudden extinguishment of gas flare in one platform was the subject of a conversation marked by an intense flow of information between the remote and the local operators. The flare stack is a combustion means used for burning flammable gas and is a protection against the risk of over-pressurizing production devices. Understanding the problem and reigniting the flare demanded exploring and eliminating possible causes throughout a process of deduction exchanging information with local operators. At a later stage, this episode generated an informal conversation among operators in the operational control center in which they compared similar situations in their own platforms and discussed changes in practices.

\section{Interpreting and comparing the use of standards and regulations}

The work routine in oil platforms involves conducting equipment tests which often demands inhibition of instruments and safety systems. Such processes are described in an internal document with guidelines for inhibition and control of security systems. Operators in the operational control center were expected to keep a physical copy of this document on their desks. The document states that it is the responsibility of the platform manager and operators in the local and in remote control rooms to follow the guidelines, analyze risks, register processes and suggest improvements. Furthermore, this documents states a hierarchy of responsibility in authorizing equipment inhibition according to equipment or system being controlled and the length of inhibition period. Operators in the control room played central role by gathering necessary documents to authorize inhibitions. In some moments, the communication between remote and local operators assumed a conflictual tone as offshore staff argued that the authorization process was rather time-consuming often unnecessarily delaying processes. In the same way, operators in the control center described mismatches between the "real life" of oil production and standards that they had to comply with as described in the guidelines document. On the other hand, an important dimension of integration is the physical proximity opening for the possibility of comparing how the standards are used in other platforms. The integration in the form of physical proximity among operators of different platforms provided the space for interpretation in such guidelines and in different moments, operators would discuss and compare procedures.

\section{Norms and regulations: Restricting variation}

The standardization of the activities in the integrated remote control room raises questions regarding organizational exploration and exploitation. Standard procedures usually have an explicit concern with operational safety and are regarded as safeguards and legal protections in case of accidents. In other words, strictly following regulatory norms 
reduces the legal liability of the company and its employees in case of major accidents. The initial implication is an increase in internal and external auditing assessing how they comply with regulatory norms. Standards are either introduced by national regulatory agencies or developed internally in the company.

The operational control center remained in many ways little connected to other departments in its operational unit indicating limited access to networks of diffusion in the company. Although it was possible to observe an intense communication with offshore platforms, the same cannot be said about communication beyond auditing and reporting between the control room and the overall operational unit. The guidelines for inhibition and control of security is an example of that. This documented goes through yearly cycles of revisions during which operators may suggest changes but do not participate in the revisions. Such findings suggest that local adaptations in the integrated control room remained largely isolated from other adaptive processes in the company.

\section{Discussion}

The analysis of findings suggests a complex interplay between the exploitation of already existing practices and everyday local adaptations emerging from processes of interactions. The conceptual framework of complex systems suggests that the main findings can be interpreted and discussed in the light of concepts of interaction and variation. Furthermore, the findings provide material to reflect upon ambidexterity in integrated operations.

\section{Interaction and factors enabling and constraining variation}

As demonstrated by March (1991), exploration demands variation. Therefore, it is important to identify factors that either facilitated or constrained variation in the IO environment. It was possible to observe that at least two factors restricted variation showing that the integrated environment was designed in a highly exploitative rather than exploratory character. The first factor was the lack of the multidisciplinarity that characterize integrated operations in most oil and gas companies. The second factor was the increasing regulation of the activity of oil platform operators in the form of externally and internally designed norms and standard procedures. The main integration that took place was in terms of work processes among operators of different platforms providing gains in terms of information flow and faster decision-making. It is indeed this context that facilitated an important dimension of variation: the professional experience of the operators. Each operator had years of experiences working in platforms that performed different roles in the web of interdependence of this unit of production.

The physical proximity among platform operators changed patterns of interaction and trust. Sharing a common workspace provided the opportunity to develop a more direct understanding of the interdependence among operators and particularities of production processes in other platforms. Furthermore, this form of integration created conditions for comparing and discussing practices. From an evolutionary perspective, such occasions can be regarded as branching points from which local adaptations may emerge.

\section{A complex interplay between exploitation and exploration: A view on ambidexterity}

The findings suggest a more dynamic perspective on ambidexterity. As presented in March (1991) and Levinthal and March (1993), the relation between exploration and 
exploitation is presented as a trade-off and a matter of explicit or implicit choices made in organizations. From a conceptual perspective, there is a much delineated difference between the two processes. In the experimental character of computer simulations from which March (1991) discusses the effect of turnover and environmental turbulence on exploration and exploitation, such differentiation is enlightening and necessary. However, in systems such as the IO control room operating in a complex environment, there is an interplay between exploration and exploitation rather than being divided by a clear temporal or spatial boundary. There was an intricate relation between exploitation in terms of pre-defined procedures and technical knowledge, and the exploration in terms of networked problem-solving and local adaptation. From this perspective, ambidexterity in exploration and exploration assumes a more organic relation between the two processes. From a knowledge management perspective, much can be learned by recognizing the relation between exploration and exploitation in the complexity of oil production.

\section{Engineering organizational history: Networks of diffusion}

Conceptualizations of complexity and evolution in organizational studies suggest a theoretical reorientation from predicting history towards engineering history with local interventions. Moreover, from a systems perspective, there is the need to match the complexity of the environment. Such conceptual assumptions might be the base for possible interventions and changes in the business model of oil and gas companies in turbulent times. Collaboration - or control, as in the case studied here - rooms are located in oil companies that are designed as professional bureaucracies divided in different units with their own functions and mechanisms of professional authority. A mutual adaptation - or mutual learning, as described by March - would require working with the structure of interactions among organizational units by strengthening communication patterns. Written norms and standard procedures are part of what is conceptualized by March as the organizational code. However, as described by March as the organizational code is not static but changing dynamically as selection occurs. In more consolidated IO environments, the multidisciplinary aspect might facilitate interaction with other units. However, in the case investigated here, the IO facility had little communication with other units of adaptation in the company, which might restrict the emergence of mutual learning between individuals and the organizational code. In such circumstances, the local adaptations as the ones observed in this IO facility remain restricted to its own unit of evolution.

In adaptive systems, norms and systems of beliefs have a rather fluid and dynamic nature. In that sense, interventions in the form of changes in the business model of oil and gas companies could benefit by understanding learning and adaptation as relatively constant processes and nurturing networks of diffusion among different units of adaptation. However, this does not mean simply increasing the flow of information - in systems already overloaded with information - but to locate specific functions of units of adaptation in terms of their of processes of interdependence and communication with other units. From a systems perspective, interventions should not be restricted to the formal organizational structure but 
identifying the "real" emergent processes of networking and nurturing processes from which the local adaptations might lead to learn in a broader perspective. From a research perspective, this is an important topic for further studies, avoiding not only a normative view towards learning, but also simplistic notions of workplace empowerment. Both from a knowledge management and from an open innovation perspective, recognizing the complex interplay between exploration and exploitation enabling flows of information and strengthening webs of influence seems to be a promising track for organizations to thrive in ever complex and uncertain environments.

\section{Limitation and further research}

The study was limited to one IO facility in a very large oil and gas company. This can be seen both as a strength and as a limitation. It provided the opportunity to observe changes in practices and local process of adaptations. On the other hand, researching exploitation and exploration in IO settings marked by multidisciplinary interaction and better conferencing possibilities with offshore personnel could bring a further insight. It is also important to investigate in more detail the information flow and knowledge transfer between the IO room to the overall company's structure. Therefore, one promising track for further research would be a social network analysis (Borgatti et al., 2014; Parise, 2007; Scott, 2013) uncovering patterns of communication, information flow between the IO facilities seen as subsystems in of complex adaptive systems. This approach enables understanding networks of diffusion, patterns of collaboration and knowledge sharing across organizational units and even beyond formal organizational boundaries.

\section{Conclusion}

The present study contributes to the understanding of the knowledge dimension of integrated operations by focusing on the interplay between the exploitation of pre-defined practices and the exploration of new possibilities. The conceptual framework of complex systems highlights the need to understand organizations beyond formal organizational design by looking at the emergent character of interactions. The analysis of findings illustrates a complex relation between the exploitative character in which the IO room was designed and the situated local adaptations emerging from local interactions among oil platform operators. The concept of integration is in itself a form of intervention that alters the structure of interactions among oil platform operators. In a moment of crisis and increasing environmental complexity, changes in the business model of oil and gas companies demand a better understanding of local adaptation processes and possibilities for networks of diffusion. In that sense, we may be able to intervene in organizational history by facilitating mutual learning between ongoing local adaptations and the organizational development in a broader perspective.

Acknowledgements

Not applicable.

Funding

Not applicable. This project did not have any external funding. 
Author's contribution

The author is responsible for the whole article. The author read and approved the final manuscript.

\section{Competing interests}

The author declares that he has no competing interests.

\section{Publisher's Note}

Springer Nature remains neutral with regard to jurisdictional claims in published maps and institutional affiliations.

Received: 13 February 2018 Accepted: 14 March 2018

Published online: 27 March 2018

\section{References}

Almklov, P., Østerlie, T., \& Haavik, T. (2014). Situated with infrastructures: Interactivity and entanglement in sensor data interpretation. Journal of the Association for Information Systems, 15(5), 263-286.

Andersen, B., Ree, G., \& Sandaker, I. (2010). A web of learning opportunities. European Journal of Education, 45(3), 481-493.

Apneseth, K., Wahl, A., \& Hollnagel, E. (2013). Measuring resilience in integrated planning. In E. Albrechtsen \& D. Besnard

(Eds.), Oil and gas, technology and humans: Risk assessment methods in organizational change (pp. 129-146).

Farnham: Ashgate.

Axelrod, R., \& Cohen, M. (2000). Harnessing complexity: Organizational implications of a scientific frontier. New York: Basic Books.

Booth, M., \& Butler, J. D. (1992). A new approach to permit to work systems offshore. Safety Science, 15(4), 309-326.

Borgatti, S., Mehra, A., Brass, D., \& Halgin, D. (2014). Social network research: Confusions, criticisms, and controversies. In

D. Brass, G. Labianca, A. Mehra, D. Halgin, \& S. Borgatti (Eds.), Contemporary perspectives on organizational social networks (research in the sociology of organizations, 40) (pp. 1-29). Bradford: Emerald Group Publishing Limited.

Bremdal, B., \& Korsvold, T. (2013). Knowledge markets and collective learning. Designing hybrid arenas for learning oriented collaboration. In T. Rosendahl \& V. Hepsø (Eds.), Integrated operations in the oil and gas industry: Sustainability and capability development (pp. 304-327). Hershey: IGl Global.

Bryman, A., \& Bell, E. (2015). Business research methods. Oxford: Oxford University Press.

Byrne, D., \& Callaghan, G. (2014). Complexity theory and the social sciences. The state of the art. London: Routledge.

Devold, H. (2013). Oil and gas production handbook: An introduction to oil and gas production. Oslo, Norway: ABB Oil and Gas Retrieved from https://ibrary.e.abb.com/public/34d5b70e18f7d6c8c1257be500438ac3/ Oil\%20and\%20gas\%20production\%20handbook\%20ed3x0_web.pdf.

Dougherty, D. (2017). Taking advantage of emergence for complex innovation eco-systems. Journal of Open Innovation: Technology, Market, and Complexity, 3(14), 1-19.

Filstad, C., \& Hepsø, V. (2009). Knowing through integrated operations in cross-disciplinary virtual teams - collaboration and self-synchronization offshore and onshore. Amsterdam: Paper presented at the Organization Learning Conference (OLC) Retrieved from http://www2.warwick.ac.uk/fac/soc/wbs/conf/olkc/archive/olkc4/papers/ 1acathrinefilstad.pdf.

Filstad, C., Hepsø, V., \& Skarholt, K. (2013). Connecting worlds through self-synchronization and boundary spanning: Crossing boundaries in virtual teams. In T. Rosendahl \& V. Hepsø (Eds.), Integrated operations in the oil and gas industry: Sustainability and capability development (pp. 76-90). Hershey: IGI Global.

Gherardi, S., \& Nicolini, D. (2002). Learning in a constellation of interconnected practices: Canon or dissonance? Journal of Management Studies, 39(4), 419-436.

Grant, R. M. (2013). The Development of Knowledge Management in the Oil and Gas Industry/El desarrollo de la Dirección del Conocimiento en la industria del petroleo y gas. Universia Business Review, 40, 92-125.

Gupta, A. K., Smith, K. G., \& Shalley, C. E. (2006). The interplay between exploration and exploitation. Academy of Management Journal, 49(4), 693-706.

Han, J. (2017). Exploitation of architectural knowledge and innovation. Journal of Open Innovation: Technology, Market, and Complexity, 3(15), 1-15.

Henderson, J., Heps $\varnothing$, V., \& Mydland, $\varnothing$. (2013). What is capability approach to integrated operations? An introduction to key concepts. In T. Rosendahl \& V. Hepsø (Eds.), Integrated operations in the oil and gas industry: Sustainability and capability development (pp. 1-20). Hershey: IGI Global.

Hepsø, V. (2006). When are we going to address organizational robustness and collaboration as something other than a residual factor? Amsterdam: Paper presented at SPE intelligent energy conference and exhibition.

Hepsø, V. (2009). 'Common' information spaces in knowledge-intensive work representation and negotiation of meaning in computer- supported collaboration rooms. In D. Jemielniak \& J. Kociatkiewicz (Eds.), Handbook of research on knowledge-intensive organizations (pp. 279-294). Hershey: IGI Global.

Hislop, D. (2009). Knowledge management in organizations: A critical introduction. Oxford: Oxford University Press.

Holland, J. (1975). Adaptation in natural and artificial systems. Ann Arbor: University of Michigan Press.

Hollnagel, E. (2013). IO, contingency, intractability and resilience. In T. Rosendahl \& V. Hepsø (Eds.), Integrated operations in the oil and gas industry: Sustainability and capability development (pp. 342-352). Hershey: IGI Global.

Johnson, S. (2001). Emergence. London: Penguin Books.

Larsen, S. (2013). Managing team leadership challenges in integrated operations. In T. Rosendahl \& V. Hepsø (Eds.), Integrated operations in the oil and gas industry: Sustainability and capability development (pp. 103-122). Hershey: IGl Global.

Lave, J., \& Wenger, E. (1991). Situated learning: Legitimate peripheral participation. New York: Cambridge University Press.

Lavie, D., Stettner, U., \& Tushman, M. L. (2010). Exploration and exploitation within and across organizations. The Academy of Management Annals, 4(1), 109-155.

Levinthal, D. A., \& March, J. G. (1993). The myopia of learning. Strategic Management Journal, 14(S2), 95-112.

Lima, C., Lima, G., Quelhas, O., \& Ferreira, R. (2015). Integrated operations: Value and approach in the oil industry. Brazilian Journal of Operations \& Production Management, 12(1), 74-87. 
Lochman, M. (2012). The future of surveillance: A survey of proven business practices for use in oil and gas. SPE Economics \& Management., 4(4), 235-247.

March, J. (1991). Exploration and exploitation in organizational learning. Organization Science, 2(1), 71-87.

March, J. G. (1994). The evolution of evolution. In J. Baum \& J. Singh (Eds.), Evolutionary dynamics of organizations (pp. 39-49). Oxford: Oxford University Press.

Miller, K. D., Zhao, M., \& Calantone, R. J. (2006). Adding interpersonal learning and tacit knowledge to March's exploration-exploitation model. Academy of Management Journal, 49(4), 709-722.

OLF - Norwegian Oil Industry Association. (2005). Integrated work processes: future processes on the Norwegian continental shelf (report). Oslo.

Ose, G. O., \& Steiro, T. J. (2013). Introducing 10 in a drilling company: Towards a resilient organization and informed decision-making? In T. Rosendahl \& V. Hepsø (Eds.), Integrated operations in the oil and gas industry: Sustainability and capability development (pp. 328-341). Hershey: IGI Global.

Padgett, J. \& Powell, W. (2012). The problem of emergence. In Authors (Eds.), The emergence of organizations and markets (pp. 1-30). Princeton, NJ: Princeton University Press.

Parise, S. (2007). Knowledge management and human resource development: An application in social network analysis methods. Advances in Developing Human Resources, 9(3), 359-383.

Rosendahl, T., Egir, A., Due-Sørensen, L., \& Ulsund, H. (2013). Integrated operations from a change management perspective. In T. Rosendahl \& V. Hepsø (Eds.), Integrated operations in the oil and gas industry: Sustainability and capability development (pp. 282-285). Hershey: IGI Global.

Rosendahl, T. \& Hepsø, V. (2013). Preface. In Authors (Eds.), Integrated operations in the oil and gas industry: sustainability and capability development (pp. xvii-xxvii). Hershey, PA: IGI Global.

Sandaker, I. (2009). A selectionist perspective on systemic and behavioral change in organizations. Journal of Organizational Behavior Management, 20(3-4), 276-293.

Scott, J. (2013). Social network analysis. London: Sage.

Steiro, T. \& Torgersen, G. (2013). The terms of interaction and concurrent learning in the definition of integrated operations. In T. Rosendahl \& V. Hepsø (Eds.), Integrated operations in the oil and gas industry: Sustainability and capability development (pp. 328-340). Hershey: IGI Global.

Stettner, U., \& Lavie, D. (2014). Ambidexterity under scrutiny: Exploration and exploitation via internal organization, alliances, and acquisitions. Strategic Management Journal, 35(13), 1903-1929.

Tsoukas, H., \& Hatch, M. J. (2001). Complex thinking, complex practice: The case for a narrative approach to organizational complexity. Human relations, 54(8), 979-1013.

Walker, G. H., Waterfield, S., \& Thompson, P. (2014). All at sea: An ergonomic analysis of oil production platform control rooms. International Journal of Industrial Ergonomics, 44(5), 723-731.

Warner Burke, W. (2013). Organization change: Theory and practice. Thousand Oaks: Sage Publications.

West, J., \& Gallagher, S. (2006). Challenges of open innovation: The paradox of firm investment in open-source software. R\&D Management, 36(3), 319-331.

Yun, J. J., Won, D., \& Park, K. (2016). Dynamics from open innovation to evolutionary change. Journal of Open Innovation: Technology, Market, and Complexity, 2(7), 1-22.

Submit your manuscript to a SpringerOpen ${ }^{\odot}$ journal and benefit from:

- Convenient online submission

- Rigorous peer review

- Open access: articles freely available online

- High visibility within the field

Retaining the copyright to your article

Submit your next manuscript at $>$ springeropen.com 